\title{
The Research and Development of Quanzhou Cultural and Creative Products Based on "Maritime Silk Road" Culture
}

\author{
Wang Xing-he \\ Liming Vocational University, Quanzhou 362000, China
}

\begin{abstract}
From the perspective of regional culture, it elaborates the characteristics of Quanzhou "Maritime Silk Road" culture and analyzes the status quo of Quanzhou cultural and creative products. Based on the analysis, it raises the great significance that the regional culture brings to the design and development of cultural and creative products and summarizes its three forms: diverse religious cultures, colorful folk art forms, unique human and architectural landscape, aiming to create economic value and spread Quanzhou "Maritime Silk Road" culture to the world as well.
\end{abstract}

\section{Introduction}

Among the domestic and foreign researches on "Cultural and Creative Products", some are about the great significance of developing cultural and creative products by Cultural Relics Departments ${ }^{[1-2]}$, and some are about the creation of cultural and creative brands, which propose the prospect of ceramics and cultural products ${ }^{[3]}$ under the pattern of "Creative Market". There are also some scholars proposing that the traditional utensil culture is the main source of regional culture and the researches of its design is important for developing cultural industries and promoting regional cultural identity. ${ }^{[4]}$ There are lots of researches on "cultural and creative products" in academia and the existing researches on Quanzhou "Maritime Silk Road" culture have also gained numerous achievements, but most of them focus on the inheritance and development of the "Maritime Silk Road" culture, especially the protection and inheritance of "intangible" cultural heritage. In the perspective of protection, some researches put forward the proposals for the protection of Islamic architectural relics in Quanzhou ${ }^{[5]}$ by comparing and analyzing the heritage of the remains of Islamic buildings such as Qingjing Mosque and Tombs of Islamic Saints from the point of view of World Heritage. In terms of cultural exchange, it was pointed out that the Buddhist music and dance in the cultural heritage of Quanzhou is the historical result of the exchange of human civilization in the Middle Ages and it is also a historical necessity for multiple music and dance cultures to collide and blend with each other ${ }^{[7]}$, according to the relationship between the Maritime Silk Road and Nanyin in Quanzhou and the exploration of their origins and introduction ways ${ }^{[6]}$. However, there are few researches on combining cultural and creative products with the "Maritime Silk Road" culture.
The design of cultural and creative products should be the embodiment of regional cultures, the combination of creativity and culture, and the protection and persistence of "original" culture. Therefore, it is urgent for designers to solve the problem that how to integrate the cultural elements of Quanzhou "Maritime Silk Road" culture into the cultural creative design and create a product with strong regional characteristics of "Maritime Silk Road" culture. Starting with religious cultures, folk art forms, human and architectural landscapes, this article analyzes its basic features, extracts its characteristic elements, and refines its design and development concepts in order to be of some help for the innovation of Quanzhou's "Maritime Silk Road" cultural and creative products.

\section{Quanzhou "Maritime Silk Road" Cultural Characteristics}

"Geographical culture is a kind of spiritual power that represents the soul of a nation, a regional taste, and the image of a city. ${ }^{[8]}$ "To some extent, the characteristics of urban culture are a manifestation of regional culture.

Quanzhou integrates the essences of the Minyue culture, the Central Plains culture, and the marine culture. It is the starting point of the Maritime Silk Road, the first batch of historical and cultural cities of the State Council, the only city that has three major categories of UN "intangible" projects in the country, and a city with profound historical and cultural background. Quanzhou is a place with a distinctive multicultural view, where Buddhism, Taoism, Islam, Christianity and the like gather, blossom and then leave a large number of precious religious relics. The East and West Towers in Kaiyuan Temple, is China's extant highest stone pavilion tower imitating wooden structure type; Taoist Laojun Statue is listed as national key protected cultural relics; 
the Holy Sepulchre is the oldest and most complete Islamic sacred site in our country; Qingjing Temple is the oldest existing Islamic temple built by Arab Muslims in China; Mani Hermitage is the only surviving Mani Buddha and Manichaeism temple in China. Thus, Quanzhou is also known as the "World Religion Museum". At the same time, Quanzhou has a rich and colorful cultural heritage, such as Quanzhou Nanyin known as the living fossil music, Luoyang Bridge being one of the "Four Ancient Famous Bridges" in China, the string puppet of "Chinese Unique", Liyuan Opera known as the living fossil opera of the Southern and Southern Song Dynasty, the traditional Gaojia dramas, "Hui'an Nv" and "Xun'fu Nv" who are famous at home and abroad because of costumes rich in local characteristics. These cultural resources with rich "Maritime Silk Road" characteristics are an important part of Quanzhou's cultural and creative products, and are also the key to expanding Quanzhou's cultural and creative industries' influence

\section{Status Quo of Quanzhou "Maritime Silk Road" Culture and Creation Products}

State Council's "Several Opinions on Promoting the Integration and Development of Cultural Creation, Design Services, and Relevant Industries" (Guo Fa (2014) No. 10) and Fujian's "Notice on Eight Measures to Promote the Integration and Development of Cultural Creation, Design Services, and Relevant Industries " (Min Zheng (2014) No. 54), both explicitly stated that the cultural and creative industries have an important role in boosting the economic transformation and upgrading, improving the quality of life of the people, and enhancing cultural soft power and the like. Taking Quanzhou as an example, the city's cultural industry added 26.9 billion yuan in 2016 , has soared 20 per cent year-on-year growth with last year and nearly 5 per cent points higher than the GDP growth rate over the same period, accounted for 5.4 per cent of the city's GDP and its proposition has continued to increase, therefore it has become the pillar industries for the national economy in Quanzhou. In recent years, the Quanzhou Municipal Party Committee and the Municipal Government have set up a leading group and its office for cultural reform and development work with the mayor being the leader, and have successively introduced a series of important policies to support the development of cultural industries and to escort the research and development of Quanzhou cultural creation products. Quanzhou has 802 cultural relics' protection units at all levels, including 31 at the national level and 83 at the provincial level. There are 601 intangible cultural heritages at all levels, levels and quantities rank among the top three in the country. These abundant cultural resources provide a vast space for the research and development of cultural and creative products. In 2013, Quanzhou was selected as the first "East Asian Cultural Capital" by virtue of its rich cultural history. In 2015, Quanzhou hosted the 14th Asian Art Festival and became the "Eastern Conference
Hall" of CCTV 2015 Spring Festival Evening. It fully proves that Quanzhou's geographical and cultural charm is gradually recognized and identified by our people, and solidifies the foundation of research and development of Quanzhou's cultural creation product.

However, few types, serious homogeneity, low technical content and relatively lack of creativity of current cultural and creative products in Quanzhou which can not fully demonstrate the characteristics of Quanzhou's "Maritime Silk Road" and then greatly reduce consumer purchase desire.

\section{Application of Regional Culture in Quanzhou's "Maritime Silk Road" Cultural and Creative Products}

\subsection{Diverse Religious Culture}

Quanzhou is known as a religious resort where Buddhism, Taoism, Islam, Catholicism, Christianity and other religions gather and live together harmoniously and leave a large number of valuable religious relics. This is a wonderful spectacle in the history of Chinese and Western cultures, so Quanzhou is also known as the "World Religion Museum" and became the world's first designated unit of UNESCO's "Multicultural Exhibition Center of the World", considering Laojun Statue, Kaiyuan Temple, Qingjing Temple, Mani Hermitage, and the like as the representative. The unique and distinctive diversity of religious culture makes the creativity, form, style and color of cultural and creative products unique and attractive.

Taking Kaiyuan Temple founded in the Tang Dynasty as an example, it is the largest Buddhist temple in Fujian Province, an important cultural relic on the southeast coast of China and it was listed as the second batch of key cultural relic protection units in the country in 1982. The East and West Towers in Kaiyuan Temple built in the Tang Dynasty, the China's extant highest stone pavilion towers imitating wooden structure type, is still standing firm under the severe test of the times, represents the outstanding achievements of Quanzhou stone architecture and carving art, is a gem of Chinese ancient stone buildings and becomes a beautiful business card of Quanzhou. Figure 1 shows a creative bookshelf originating from the East and West Towers. The bookshelf extracts the East-West Towers' silhouette as a design element, and takes the meaning of the mutual protection of the two standing-firm towers. The reddishbrown wooden bookshelf with novel and practical design puts the original boring book-laying behaviour into a strong cultural atmosphere to enhance the interaction between people and products and let the bond of emotions tightly integrate people and products together ${ }^{[9]}$ to leave an indelible impression on consumers, and then deepen their impression of the city of Quanzhou. 


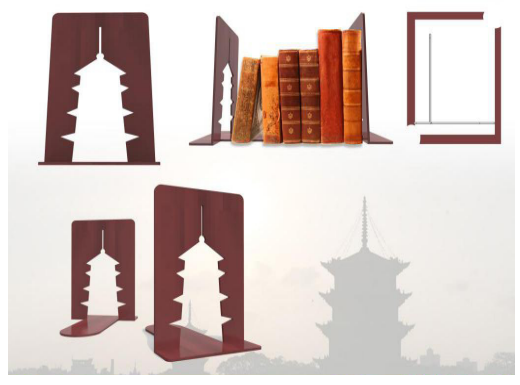

Figure 1 "East and West Towers" Bookshelf Design

Taking Qingjing Temple as an example, it was built on the architectural form of the Islamic Chapel of Damascus in Syria. It is one of the four major Islamic temples in China and is the only temple in the Song Dynasty that has been preserved so far. It was among the first batch of key cultural relic protection units announced by the State Council, is witnesses of friendship and cultural exchanges between China and Arab countries and is one of the important historical sites of overseas exchanges in Quanzhou. Figure 2 shows a creative U disk originating from the "Qingjing Temple". The product is based on the Qinging Temple gatehouse, injects Islamic sanctity and purity into the $\mathrm{U}$ disk design carrier, to brings to consumers a sensation that their ears needs a moment of calmness in the process of eyecatching in the East and West from ancient to modern times. The $U$ disk design is dominated by green and white colour, and its telescopic operation mode not only protects the interface, but also adds aesthetics and great geographical features.

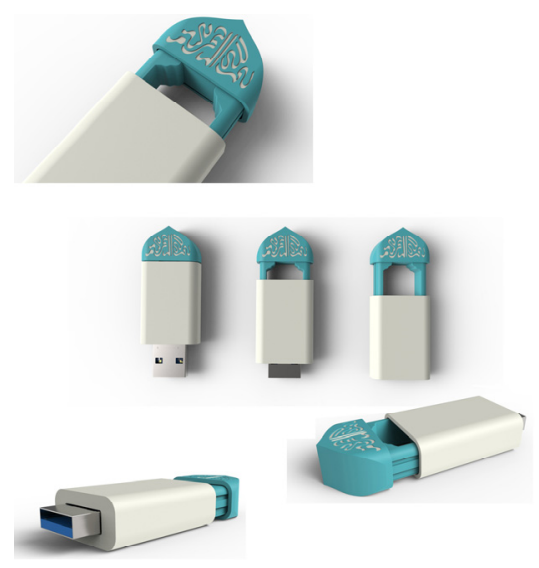

Figure 2 “Qingjing Temple" U Disk Design

\subsection{Colorful Folk Art Features}

Cultural and artistic forms flourish. Quanzhou Nanyin, with its rich and profound historical and cultural heritage, is one of the country's oldest existing musical species. It has accompanied Quanzhou people's daily life for thousands of years, is a living fossil of musical culture and was listed into the human intangible cultural heritage representative list by UNESCO in 2009. Liyuan Opera known as the living fossil opera of the Southern and Southern Song Dynasty and the traditional Gaojia dramas are still the Quanzhou people's daily entertainment. At the same time, the Quanzhou string puppet of "Chinese Unique", unique palm puppets, chest dancing and other traditional cultural performances, which are amusing and exquisite, let the people dwell upon with great relish. Rich and colourful art culture is an important component of cultural and creative products and has a distinct cultural tension.

Take Nanyin as an example, Quanzhou Nanyin also known as "Chord Tube" which was originated in the Qianqin and formed in the Song Dynasty, is a fusion of the Central Plains music culture and local folk music, and is the oldest Han ancient music in China ${ }^{[10]}$. It retains the Han people's ancient ethnic singing before the Tang Dynasty and sings with the Southern Fujian Dialect of Quanzhou. It has the cultural expressions of the ancient music of the Central Plains and is very characteristic. In 2006, it was approved by the State Council to be included in the first batch of state-level intangible cultural heritage. In 2009, Nanyin (Quanzhou Chord Tube) was formally listed by UNESCO in the representative list of human intangible cultural heritage. Figure 3 is the "Sweet Voice" cosmetic design. These cosmetics extract the shapes of Nanyin traditional musical instruments as a design element to put the feelings of the town people miss of families and nostalgia into cosmetics. The novel practical design full of stories and implication combine makeup interest and humanistic feelings to expose the consumers to the sound of Nanyin music, and arouse their new emotional experience.
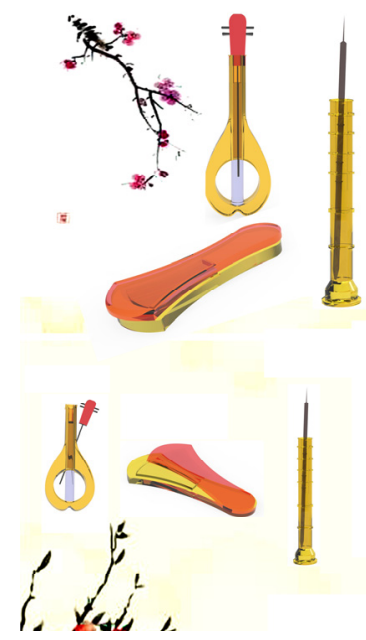

Figure 3 "Sweet Voice" Cosmetic Design

Taking Liyuan Opera, the living fossil of the ancient Southern opera, as an example, which is one kind of old drama originated in Quanzhou during the Song and Yuan Dynasties and has spread widely in Quanzhou, Xiamen, Zhangzhou and other places, being included in the first batch of state-level intangible cultural heritage. Figure 4 is the "Southern Opera" doll alarm clock design. The product is designed with the theme of Liyuan Opera, uses the cute models of the character Liyuan Opera characters and combine the alarm clock, charging, sound together with a memory card for the customers to freely choose their favourite music. These designs preserve the city's memories in cultural and creative gifts, interpret 
urban aesthetics, tell city stories, and highlight the uniqueness of Quanzhou's geographically distinctive products through modern design language.

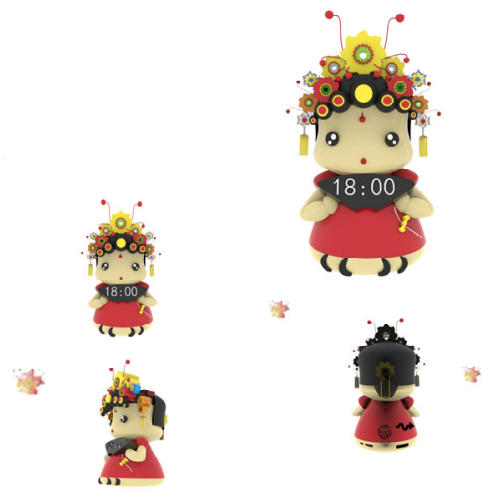

Figure 4 "Southern Opera" Doll Alarm Clock

\subsection{Unique Cultural and Architectural Landscape}

Quanzhou is located on the southeastern coast and forms a unique humanistic feature, such as the Hui'an Nv with its distinctive clothing features "feudal head, democratic belly, saving shirt, waste of pants." At the same time, its architecture not only has the characteristics of traditional Chinese architecture, but also has formed its own unique architectural style because of its environment, such as "Da Cuo", "Qi Lou" and the like. All these have become an important carrier of cultural and creative products.

Take Hui'an $\mathrm{Nv}$ as an example, they refer to the female of Huidong Peninsula in Hui'an County, Quanzhou. Hui'an County is located in the coastal area, with many people but little land in the area. Because men in the family need to go fishing or go out for a living for a long time under the imperatives of life, Hui'an female bravely shoulder heavy burdens, support their parents in-laws, teach their children, can do all kinds of unskilled work, heavy work and skilled work well. At the same time, their "feudal head, democratic belly, saving shirt, waste of pants" distinctive local characteristics clothing features let them known both at home and abroad. Hui' an Nv spirit is a vivid portrayal of Quanzhou people's spirit of "Love to Fight and Win", and has become a unique cultural feature of Quanzhou. Figure 5 shows the design of the "Hui' an Nv" tumbler alarm clock.

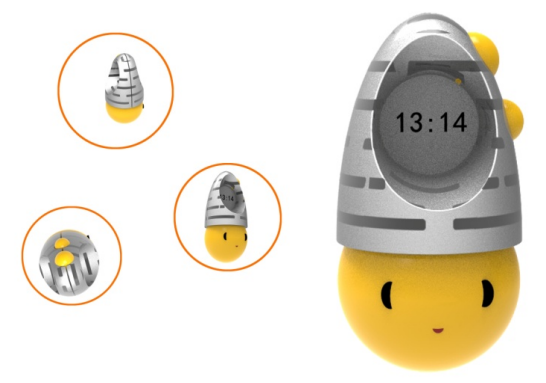

Figure 5 "Hui' an Nv" Tumbler Alarm Clock Design

The "Hui' an Nv" tumbler alarm clock is designed based on Hui' an female image and adopts the image composition method to extract its concise and practical features, and to refine the design elements of the "feudal head and democratic belly" of Hui'an Nv's clothing using the tumbler style to make alarm clocks both practical and geographically attractive and attract more consumers to purchase.

As a carrier of historical culture, architecture not only shows the local folk customs, but also reflects the local artistic achievements and is deeply influenced by local culture. The architecture of Quanzhou not only has the characteristics of a wooden frame roof, a clear symmetry of the central axis and the like of a traditional Chinese building, but also forms a distinctive architectural style due to the southeastern coastal environment and its function of the overseas traffic and trade ports. It has absorbed the essence of Chinese traditional culture, marine culture and the Minyue culture, and has become an important carrier of Maritime Silk Road culture. Different from traditional Chinese architecture using grey bricks as major materials in building walls, Minnan area would like red bricks in building houses, and red brick houses are a major feature of Minnan architecture. They are well-known in the world with beautiful shape and rich local characteristics. Quanzhou red brick building is a typical representative of the "Red Brick District" culture ${ }^{[8] . ~ T a k e ~ r e d ~ b r i c k ~ c u o ~ a s ~ a n ~ e x a m p l e, ~}$ "Cuo" represents house in the dialect of Minnan. The red brick cuo is the house covered with red brick, which is a typical traditional dwelling and the most representative traditional building in southern Fujian. Its exquisite carvings not only show the mature sculpture art of southern Fujian, but also can exhibit the impact of Islam, Indian Buddhism, Nanyang culture and Western architectural arts. Therefore, it is praised as "Southern Fujian Architecture Grand View Garden". Figure 6 is the "Dovetail Ridge" book and pen holder.

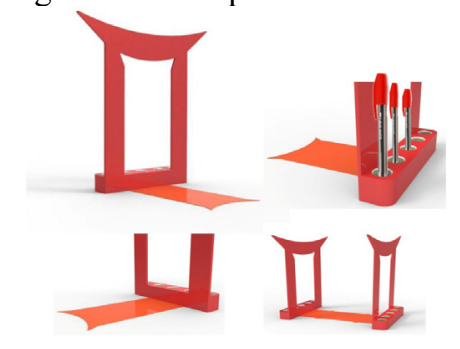

Figure 6 "Dovetail Ridge" Book and Pen Holder Design

The design of the "Dovetail Ridge" book and pen holder is mainly drawn from the dovetail ridge shape of the Quanzhou ancient red brick building and its chief colour is red as the brick. The design contains the bright, open-minded and tough character of the Minnan people and their prayer for good life, and conveys the deep and unique heritage of the red brick culture through the brush and pen holder.

\section{Conclusion}

Cultural and creative products are unique commodities, which firstly satisfy the functions of products, and 
should also have rich cultural connotations and distinctive regional characteristics to satisfy consumers' unique emotional experiences and serve as bridges between consumers and local cultural exchanges. Therefore, the research and development of cultural and creative products should be an organic combination of design art and regional culture to make their unique creativity, shape and colour. When consumers use cultural and creative products, they can deepen their understanding of the local cultural traditions and customs to achieve emotional resonance. In the combination process, design art and regional culture complement and promote mutually.

\section{Acknowledgment}

[Fund Project] Quanzhou Social Science Planning Project (2017E18); Quanzhou City College Youth Leadership (Professional) Leader Training Plan

\section{References}

1. Xu Yaoxin. It is of great significance for cultural relics units to develop cultural and creative products, New Century Library, 11(2016)

2. Cen Ke. Get rid of "identity imprisonment" and promote the development of cultural and creative products, Cultural Focus, 2 (2017)

3. Liu Qing. Branding: The Outlet of Jingdezhen Ceramics Cultural and Creative Products under the "Creative Market" Model, Journal of Ceramics, 37(2016)

4. Zhao Decheng, Sha Ying. Regional imagery extraction of ancient artifacts and regional innovative design of products, Packaging Engineering, 38(2017)

5. Wu Yuxiang, Guan Ruiming. Heritage Values and Protection Planning of Islamic Architecture Remains in Quanzhou. Journal of Huaqiao University(Natural Science), 35 (2014)

6. Wang Yaohua. The Origin of the Foreign Musical Factors in the "Four Famous Musicians" Section of Quanzhou Nanyin and the Examination of Their Incoming Routes. Music Research, 5 (2015)

7. Zhang Yuan. The Study of Buddhism Music and Dance in the Cultural Relics of Quanzhou Maritime Silk Road—Taking "Flying Sky" as an Example. Music Research, 2 (2015):

8. Wang Xinghe. Tourism Creative Product Design Based on Quanzhou Regional Culture. Journal of Liming Vocational University, 2 (2015)

9. LIU Xiaohong. Research on the Development and Design of Fujian Hakka Tulou Culture Products[J]. Packaging Engineering, 5 (2012)

10. Wang Shan. Quanzhou Nanyin. Fuzhou: Fujian People's Publishing House, (2009) 